\title{
Knowledge, attitude, practice (KAP) and dietary intake of young university athletes following sports nutrition education
}

\author{
Nur Najiah Zaidani Kamarun Zaman, Ayu Suzailiana Muhamad \& Mohd Rahimi \\ Che Jusoh
}

${ }^{1}$ Exercise \& Sports Science Programme, School of Health Sciences, Health Campus

Universiti Sains Malaysia, 16150 Kota Bharu, Kelantan, Malaysia

\begin{abstract}
Introduction: Nutrition plays a vital role in sports. Athletes must understand the importance of diet and ensure that they meet the nutrient requirements to enhance sports performance. The lack of understanding in sports nutrition will lead to poor dietary practices that can cause detrimental effects on athletic achievements. This study aims to evaluate the effects of knowledge, attitude, and practice (KAP) regarding sports nutrition and dietary intake among young university athletes. Methods: Twenty-one local university athletes (23.8 \pm 3.4 years) were recruited, and their anthropometric and socio-demographic data were assessed. All participants attended a 1-day sports nutrition class. The KAP-Sports nutrition questionnaire was administered. Three days of dietary intake were also recorded at the same timepoints among the participants. Results: There was a significant increment $(p<0.05)$ in the mean scores for KAP among the participants. Total energy and total carbohydrate intakes per day were significantly increased $(p<0.05)$. However, overall protein and fat intakes did not improve as the readings were higher than the recommended values. Conclusion: In this study, sports nutrition education improved participants' KAP, but not the actual dietary intake. Changes in habit require more effort, with extra attention on protein and fat intakes.
\end{abstract}

Keywords: Knowledge, attitudes, and practice (KAP), dietary intake, sports nutrition education, athletes

\section{INTRODUCTION}

Appropriate nutrition intake is crucial for optimal athletic performance as it supplies fuel for biological work and energy for movement. It is also important for building and synthesising new tissues, repairing the cells, balancing fluid and electrolyte levels, and regulating all metabolic processes (McArdle, Katch \& Katch, 2013). Previous study has reported that proper and optimal nutrient intake is associated with peak performance, while nutrient deficiencies may diminish the athletes' performance (Hornstrom et al., 2011). Athletes are aware that the right nutrition is important to optimise their performance (Kiens, Ivy \& Burke, 2004). However, they still lack knowledge, and have poor attitudes and practice towards sports nutrition (Jacobson, Sobonya \& Ransone, 2001).

\footnotetext{
*Corresponding author: Dr Mohd Rahimi Che Jusoh

Exercise \& Sports Science Programme, School of Health Sciences,

Health Campus Universiti Sains Malaysia, 16150 Kota Bharu, Kelantan, Malaysia

E-mail: rahimichejusoh@usm.my

doi: https: / / doi.org/10.31246/mjn-2020-0098
} 
Energy balance is vital for athletes to improve their exercise capacity. The optimal food intake must be equivalent to the demand for energy usage during training or competition. If the energy is not well distributed, it may lead to unfavourable alterations in the athletes' body function, as well as their body systems, thus reducing the capacity to exercise (Arieli \& Constantini, 2012). Some athletes and coaches in aesthetic sports like diving or gymnastics believe that a reduction in weight or body fat by controlling energy balance will improve the performance of the athletes (Deutz et al., 2000). However, controlling food intake without proper knowledge in sports nutrition might lead to problems such as undernutrition. Therefore, giving the right nutrition knowledge to athletes especially on how to eat according to their body needs, daily calorie intake, and proper foods and supplement selection is vital to maintain their health and optimise their sports performance, as well as to speed up recovery process and to prevent injuries (Fink \& Mikesky, 2018).

Athletes' knowledge on sports nutrition needs to be assessed in order to ensure correct practices, and at the same time, to avoid wrong information, myths, and misconceptions (Paugh, 2005). Assessing athletes' dietary intake will provide an overview of their actual dietary practices and basic understanding of nutrition knowledge. Therefore, it is good to assess both dietary intake and nutrition knowledge as these may help to develop a better nutritional plan besides providing information about desirable eating behaviours (Paugh, 2005). Furthermore, this information may be useful in providing nutrition counselling for athletes if they have issues with nutrition intakes (Paugh, 2005).

Studies have reported that athletes always have difficulty in achieving optimal nutrition due to a lack of understanding of basic nutrition concepts (Dunn, Turner \& Denny, 2007). The requirement of nutritional intake among athletes is different from the general population and also different according to their type of sport. Thus, athletes need to be educated on the requirement of food intake based on their sports category (Trabucco, Nikoic \& Mirkovic, 2013). To date, information regarding the level of knowledge, attitude, and practice (KAP) on sports nutrition among young university athletes are scarce. Thus, this study aims to determine the KAP level, as well as to evaluate the effectiveness of sports nutrition education on KAP and dietary intake among young university athletes.

\section{MATERIALS AND METHODS}

\section{Study design}

This was an intervention study with preand post-test measurements. This study declares no conflict of interest, and ethical approval was obtained from the Human Research Ethics Committee of Universiti Sains Malaysia (USM) (USM/ JEPeM/18120796).

\section{Participants and sample size calculation}

Participants were recruited voluntarily among the Universiti Sains Malaysia (USM) students via purposive sampling approach. The inclusion criteria were university athletes who had participated in any competition at least at the university level, healthy, aged between 19 to 30 years old, and did not have any formal or informal nutrition classes. The exclusion criteria were those with health problems, took part in other research interventions, and on a special diet as per doctor's recommendation. The sample size calculation was carried out based on a previous study (Siti Soraya et al., 2018) by using PS Power and Sample Size Calculation Version 3.1.2. Twenty- 
one participants were recruited for the study with the consideration of a $10 \%$ drop-out.

\section{Study procedures}

At the beginning of the study, the objectives and procedures of the study were explained to the participants. Their informed consent were obtained to indicate their willingness to participate in the study. Pre-test measurements were then carried out on each participant. The pre-test assessments included anthropometry (height and weight measurements), sociodemographic data, administration of the KAP-Sports nutrition questionnaire, and recording of dietary intake for three days (two weekdays and one day on the weekend). After pre-test, the participants attended a one-day sports nutrition class conducted by the sports nutrition lecturers from USM. Four weeks after attending the class, posttest measurements were conducted, which included administration of the KAP-Sports nutrition questionnaire and recording of dietary intake for three days.

\section{KAP-Sports nutrition questionnaire}

A validated questionnaire developed by Siti Soraya et al. (2018) and Hornstrom et al. (2011) was used in this study. The Cronbach's alpha value was 0.79 , and the questionnaire was divided into three sections. These sections were knowledge that consisted of 25 questions, attitude with 20 questions, and practice with 12 questions. The total score for the knowledge section was obtained by summing up the points for all questions. One point was given for each correct answer, while zero point was given for each incorrect answer. The maximum score for the knowledge section was 25 points, where 20 to 25 points was categorised as high level of knowledge, 15 to 19 points as moderate level, and 0 to 14 points as low level.
The total score for the attitude section was also calculated by adding the points obtained for all questions. The maximum score for the attitude section was 80 points with 65 to 80 points categorised as positive attitude, 48 to 64 points categorised as neutral, and 0 to 47 points categorised as negative attitude. Similarly, for the practice section, the total score was calculated by adding the points obtained for all 12 questions. The maximum score for the practice section was 48 points. The total practice scores were categorised into three groups: good (40 - 48 points), fair ( $20-39$ points), and poor (0 -19 points).

\section{Anthropometric measurements}

Participant's body weight was measured to the nearest $0.1 \mathrm{~kg}$ using a digital weighing scale (Tanita, UM-076, Japan), whereas height was measured using a portable stadiometer (SECA 217, SECA Corp., Germany) to the nearest $0.1 \mathrm{~cm}$. Body mass index (BMI) was calculated in $\mathrm{kg} / \mathrm{m}^{2}$ and categorised into four categories based on the World Health Organization (WHO) reference of underweight, normal, overweight, and obese (WHO, 2004).

\section{Dietary assessment}

The three-day dietary intake record was self-administered by the participants using a food diary. The participants were required to record the types and amount of their entire food and beverage intakes, weight information, brand name, portion sizes, and food preparation for three days - two weekdays and one day on the weekend. A photo album consisting of utensils and food designs in three common sizes (small, medium, and large) was provided as a resource to assist the participants in recording their dietary intake. To ensure the accuracy of recording, the participants were briefed by the researchers at pretest on how to record their dietary intake 
in the food diary. After post-test, total energy and macronutrient intakes of the participants were examined by the researchers with the help from a dietitian by using the Nutritionist Pro software. Expert judgement was used in analysing food items that were not in the food composition tables (e.g. purchased and pre-cooked foods, supplements, etc.).

\section{Sports nutrition class}

All participants attended a one-day sports nutrition class conducted by the sports nutrition lecturers from USM who were not part of the research team. The topics covered during the sports nutrition class are listed in Box 1. The lessons were conducted in the form of three separate lectures and discussions, which began from 8:00 a.m. and ended at 5:30 p.m. Each lecture and discussion session covered 2-3 topics and was conducted for about $2.5-3$ hours with a short break in between each session (Box 1).

\section{Statistical analysis}

The completed questionnaires were compiled and statistically analysed using the SPSS software Version 24. Descriptive analysis and paired t-test were used to analyse the data. Data were checked for normality by using the histogram, and $p<0.05$ was used to indicate a statistical significance. Results were reported as mean \pm standard deviation $(S D)$.

\section{RESULTS}

\section{Participants' characteristics and demographic data}

The demographic data of the participants are presented in Table 1. A total of 21 participants completed the pre- and

Box 1. Topics covered during the sports nutrition class

\section{Lecture \& Discussion 1}

1. Food and healthy nutrition

1.1. Food pyramid, food plate, food exchange, serving size

2. Macronutrients

1.1. Recommended Nutrient Intakes (RNI) for CHO, protein, fat and fibre

1.2. Role of the macronutrients, types and quantity

3. Micronutrient

1.1. Determine recommended nutrient intakes of several important minerals and vitamins

1.2. Explain roles of the minerals and vitamins in metabolic pathways and exercise

\section{Lecture \& Discussion 2}

4. Fluid and hydration

4.1. Understand functions and importance of water and electrolytes for human body

4.2. Describe fluid intake requirement at pre-, during and after exercise/competition

5. Nutrition before, during and after training or competition

5.1. Describe and plan pre-training, during training and post-training meals

\section{Lecture \& Discussion 3}

6. Dietary supplement

6.1. Discuss current/popular supplements (protein powder, caffeine)

6.2. Discuss banned supplements

7. Energy balance and weight management

7.1. Understand importance of energy balance and weight management

7.2. Understand how to calculate energy balance

7.3. Discuss weight management strategies 
post-test. The participants were USM student athletes who were actively involved in various types of sports and had participated in competition at least at the university level. The participants comprised 17 Malays, one Chinese, and three from other ethnicities. The distribution of male and female participants was $52.4 \%$ and $47.6 \%$, respectively. Mean age of male participants was $22.8 \pm 1.8$ years, whereas mean age of female participants was $24.6 \pm 4.6$ years. The education level of the participants varied, ranging from diploma to $\mathrm{PhD}$ level, with most of them being undergraduate students. Participant's BMI was calculated based on the participant's weight and height measured at pre-test and the results showed that all participants had normal BMI, which is between 18.5 and 24.9 $\mathrm{kg} / \mathrm{m}^{2}$ (WHO, 2004). Majority of male $(33.3 \%)$ and female $(28.5 \%)$ participants were football players and aerobic dancers, respectively.

\section{Knowledge}

At pre-test, results in Table 2 show that majority of the participants (57.1\%) had a moderate level of knowledge on sports nutrition. None of them were categorised in the low level. After attending the sports nutrition class, post-test results showed that there was an increment in the knowledge level of the participants, where a majority $(76.2 \%)$ of them were categorised as having a high level of knowledge on sports nutrition. Table 3 shows the results of paired $t$-test analysis, which compared the mean scores of the participants' knowledge between pre- and post-test for male and female participants. Mean score for male participants were significantly increased $(p=0.022)$ from $19.0 \pm 2.2$ (moderate level) at pre-test to $21.0 \pm 1.8$ (high level)

Table 1. Characteristics and socio-demography of participants $(N=21)$

\begin{tabular}{lccc}
\hline Variables & Male & Female & Overall \\
\hline Age (years), Mean $\pm S D$ & $22.8 \pm 1.8$ & $24.6 \pm 4.6$ & $23.8 \pm 3.4$ \\
Gender, $n(\%)$ & $11(52.4)$ & $10(47.6)$ & $21(100.0)$ \\
BMI $\left(\mathrm{kg} / \mathrm{m}^{2}\right)$, Mean $\pm S D$ & $23.5 \pm 3.7$ & $21.9 \pm 2.4$ & $22.3 \pm 3.1$ \\
Ethnicity, $n(\%)$ & & & \\
$\quad$ Malay & $10(90.9)$ & $7(70.0)$ & $17(81.0)$ \\
Chinese & $1(9.1)$ & $0(0.0)$ & $1(4.8)$ \\
Others & $0(0.0)$ & $3(30.0)$ & $3(14.2)$ \\
Types of sports, $n(\%)$ & & & \\
Badminton & $3(27.3)$ & $0(0.0)$ & $3(14.2)$ \\
Basketball & $0(0.0)$ & $1(10.0)$ & $7(4.8)$ \\
Football & $7(63.6)$ & $0(0.0)$ & $1(4.3)$ \\
Frisbee & $0(0.0)$ & $1(10.0)$ & $6(28.5)$ \\
Aerobic dance & $0(0.0)$ & $6(60.0)$ & $1(4.8)$ \\
Taekwondo & $1(9.1)$ & $0(0.0)$ & $1(4.8)$ \\
Track \& field & $0(0.0)$ & $1(10.0)$ & \\
Volleyball & $0(0.0)$ & $1(10.0)$ & $1(4.8)$ \\
Education level, $n(\%)$ & & & $14(66.7)$ \\
Diploma & $1(9.1)$ & $0(0.0)$ & $5(23.7)$ \\
Degree & $7(63.6)$ & $7(70.0)$ & $1(4.8)$ \\
Master & $3(27.3)$ & $2(20.0)$ & $1(10.0)$ \\
Ph.D. & $0(0.0)$ & &
\end{tabular}


at post-test. Female participants also showed significant increment $(p=0.007)$ in their knowledge score from 19.0 22.4 (moderate level) at pre-test to $21.0 \pm 1.4$ (high level) at post-test.

\section{Attitude}

As shown in Table 2, at pre-test, $57.1 \%$ of the participants had a neutral attitude towards sports nutrition. Majority of the male participants (63.6\%) showed a positive attitude towards sports nutrition, while majority of the female participants $(80.0 \%)$ showed neutral attitude. None of the male and female participants scored below 48 points (negative attitude). At post-test, the level of attitude towards sports nutrition was increased in both genders, with majority of the participants (61.9\%) having a positive attitude. In Table 3 , the mean score of attitude for male participants increased from 65.0 \pm 7.1 (positive attitude) at pre-test to $70.0 \pm 6.9$ (positive attitude) at post-test; however, this change was not significantly different $(p=0.090)$. Female participants showed significant increment $(p=0.035)$ in attitude score from moderate $(61.0 \pm 4.5)$ at pre-test to positive $(65.0 \pm 6.1)$ at posttest.

\section{Practice}

Table 2 also shows the dietary practice scores among the participants at preand post-test. Overall, $72.7 \%$ and $70.0 \%$ of male and female participants, respectively, showed poor level of practice in nutrition. Four weeks after attending the sports nutrition class (post-test), majority of the participants $(71.4 \%)$ showed fair level of practice in nutrition. As shown in Table 3, the mean score of practice for male participants was significantly increased $(p=0.012)$ from $27.0 \pm 5.0$ (poor level) at pre-test to $32.0 \pm 4.5$ (fair level) at post-test. Female participants also showed significant

Table 2. Knowledge, attitude, and practice on sports nutrition among participants

\begin{tabular}{|c|c|c|c|c|c|c|}
\hline \multirow[t]{2}{*}{ Variables } & \multicolumn{3}{|c|}{ Pre-test, $n$ (\%) } & \multicolumn{3}{|c|}{ Post-test, $n(\%)$} \\
\hline & Male & Female & Overall & Male & Female & Overall \\
\hline \multicolumn{7}{|l|}{ Knowledge } \\
\hline $\begin{array}{l}\text { High } \\
(20-25 \text { points })\end{array}$ & 5 (45.5) & 4 (40.0) & 9 (42.9) & 8 (72.7) & $8(80.0)$ & $16(76.2)$ \\
\hline $\begin{array}{l}\text { Moderate } \\
\text { (15 - } 19 \text { points) } \\
\text { Low }\end{array}$ & $6(54.5)$ & $6(60.0)$ & $12(57.1)$ & $3(27.3)$ & $2(20.0)$ & $5(23.8)$ \\
\hline$(0-14$ points $)$ & $0(0.0)$ & $0(0.0)$ & $0(0.0)$ & $0(0.0)$ & $0(0.0)$ & $0(0.0)$ \\
\hline \multicolumn{7}{|l|}{ Attitude } \\
\hline $\begin{array}{l}\text { Positive } \\
\text { (65 - } 80 \text { points) } \\
\text { Neutral }\end{array}$ & 7 (63.6) & $2(20.0)$ & $9(42.9)$ & $8(72.7)$ & $5(50.0)$ & 13 (61.9) \\
\hline $\begin{array}{l}\text { (48 - } 64 \text { points) } \\
\text { Negative }\end{array}$ & $4(36.4)$ & $8(80.0)$ & $12(57.1)$ & $3(27.3)$ & $5(50.0)$ & $8(38.1)$ \\
\hline$(0-47$ points $)$ & $0(0.0)$ & $0(0.0)$ & $0(0.0)$ & $0(0.0)$ & $0(0.0)$ & $0(0.0)$ \\
\hline \multicolumn{7}{|l|}{ Practice } \\
\hline $\begin{array}{l}\text { Good } \\
(40-48 \text { points })\end{array}$ & $0(0.0)$ & $1(10.0)$ & $1(4.8)$ & $1(9.1)$ & $0(0.0)$ & $1(4.8)$ \\
\hline $\begin{array}{l}\text { Fair } \\
(29-39 \text { points })\end{array}$ & $3(27.3)$ & $2(20.0)$ & $5(23.8)$ & $8(72.7)$ & 7 (70.0) & 15 (71.4) \\
\hline $\begin{array}{l}\text { Poor } \\
(0-28 \text { points })\end{array}$ & 8 (72.7) & 7 (70.0) & $15(71.4)$ & $2(18.2)$ & $3(30.0)$ & $5(23.8)$ \\
\hline
\end{tabular}


Table 3. Comparison of KAP's mean scores between pre- and post-test

\begin{tabular}{cccc}
\hline Variables & Pre-test & Post-test & p-value \\
\cline { 2 - 3 } & Mean $\pm S D$ & Mean $\pm S D$ & \\
\hline Knowledge & & & \\
Male & $19.0 \pm 2.2$ & $21.0 \pm 1.8$ & $0.022^{*}$ \\
Female & $19.0 \pm 2.4$ & $21.0 \pm 1.4$ & $0.007^{*}$ \\
$\quad$ Overall & $19.0 \pm 2.2$ & $21.0 \pm 1.7$ & $0.001^{*}$ \\
Attitude & & & \\
Male & $65.0 \pm 7.1$ & $70.0 \pm 6.9$ & 0.090 \\
Female & $61.0 \pm 4.5$ & $65.0 \pm 6.1$ & $0.035^{*}$ \\
Overall & $63.0 \pm 6.2$ & $67.0 \pm 6.9$ & $0.009^{*}$ \\
Practice & & & \\
Male & $27.0 \pm 5.0$ & $32.0 \pm 4.5$ & $0.012^{*}$ \\
Female & $27.0 \pm 3.8$ & $31.0 \pm 4.5$ & $0.042^{*}$ \\
Overall & $27.0 \pm 4.4$ & $31.0 \pm 4.5$ & $0.001^{*}$ \\
\hline
\end{tabular}

*significantly different at $p<0.05 ; N=21$

increment $(\mathrm{p}=0.042)$ in their mean score of practice from $27.0 \pm 3.8$ (poor level) at pre-test to $31.0 \pm 4.5$ (fair level) at posttest.

\section{Dietary intake}

Mean total energy and macronutrient intakes among the participants are shown in Table 4. The mean total energy intake for both male $(1389 \pm 190 \mathrm{kcal}$ at pre-test; $2172 \pm 267 \mathrm{kcal}$ at post-test) and female $(1227 \pm 202 \mathrm{kcal}$ at pre-test; $1962 \pm 389 \mathrm{kcal}$ at post-test) participants were significantly increased $(p=0.001)$ from pre- to post-test. Although both genders showed an increment in total energy intake, the values were still below the recommended RNI values, which are between 2520-2740 kcal for males and 2080-2370 kcal for females.

The average carbohydrate intake per day had also significantly increased $(p=0.002)$ from $168.4 \pm 31.2 \mathrm{~g}$ at pre-test to $253.7 \pm 65.2 \mathrm{~g}$ at post-test for male participants, and it was significantly increased $(p=0.001)$ from $152.5 \pm 30.9 \mathrm{~g}$ at pre-test to $235.9 \pm 52.5 \mathrm{~g}$ at post-test for female participants. The pre-test average carbohydrate intake per day for both genders was less than the recommended nutrient intake (RNI) values, but after attending the sports nutrition class, the values were increased and fell within the recommended RNI values; 200-330g for males and 180-230 $\mathrm{g}$ for females. However, the percentage of carbohydrate intake between pre- and post-test in both genders were not significantly different $(p>0.05)$. It was less than the recommended percentage by RNI, which is between $55-70 \%$.

Table 4 also shows that total protein intake per day for both male $(54.6 \pm 13.3$ g) and female (49.2 $\pm 13.2 \mathrm{~g})$ participants at pre-test was less than RNI. However, total protein intake was significantly increased $(p<0.05)$ at post-test and was more than RNI. As for protein intake percentage, its value in both genders at pre- and post-test was within the recommended RNI value (15-20\%) and not significantly different $(p>0.05)$.

Total fat intake per day in male participants at pre-test $(91.4 \pm 121.7 \mathrm{~g})$ was higher than the RNI (62-75g), whereby the value was not significantly different $(p=0.959)$ compared to post-test $(89.5 \pm 16.6 \mathrm{~g})$. On the other hand, total fat intake per day in female participants $(46.9 \pm 9.6 \mathrm{~g})$ was less than RNI at pre-test but had significantly increased ( $p=0.001)$ beyond the recommendation at posttest $(79.4 \pm 18.5 \mathrm{~g})$. In both genders, the percentage of fat intake was higher $(>30 \%)$ than the recommended RNI value $(25-30 \%)$. There was no significant difference in the percentage between preand post-test in both genders $(p>0.05)$.

\section{DISCUSSION}

This study was conducted to examine the effects of sports nutrition class on knowledge, attitude, and practice (KAP) regarding sports nutrition, as well as dietary intake of young university athletes. All participants attended a one-day class on sports nutrition as an intervention in this study. The topics covered in this class are listed in Table 
Table 4. Comparison of total energy and macronutrient intakes per day between pre- and post-test

\begin{tabular}{|c|c|c|c|c|}
\hline \multirow{2}{*}{ Variables } & Pre-test & Post-test & \multirow{2}{*}{$p$-value } & \multirow{2}{*}{$\begin{array}{c}\text { Recommended } \\
\text { RNI value }\end{array}$} \\
\hline & Mean $\pm S D$ & Mean $\pm S D$ & & \\
\hline \multicolumn{5}{|c|}{ Total energy (kcal) } \\
\hline Male & $1389 \pm 190$ & $2172 \pm 267$ & $0.001^{*}$ & $2520-2740$ \\
\hline Female & $1227 \pm 202$ & $1962 \pm 389$ & $0.001^{*}$ & $2080-2370$ \\
\hline \multicolumn{5}{|c|}{ Total carbohydrate intake (g) } \\
\hline Male & $168.4 \pm 31.2$ & $253.7 \pm 65.2$ & $0.002 *$ & $200-330$ \\
\hline Female & $152.5 \pm 30.9$ & $235.9 \pm 52.5$ & $0.001^{*}$ & $180-230$ \\
\hline \multicolumn{5}{|c|}{ Carbohydrate intake (\%) } \\
\hline Male & $48.7 \pm 7.3$ & $46.6 \pm 9.5$ & 0.404 & $55-70$ \\
\hline Female & $49.6 \pm 5.0$ & $48.4 \pm 5.6$ & 0.582 & $55-70$ \\
\hline \multicolumn{5}{|c|}{ Total protein intake (g) } \\
\hline Male & $54.7 \pm 13.3$ & $88.4 \pm 33.7$ & $0.006^{*}$ & $61-62$ \\
\hline Female & $49.2 \pm 13.2$ & $76.1 \pm 25.8$ & $0.009 *$ & $52-53$ \\
\hline \multicolumn{5}{|c|}{ Protein intake (\%) } \\
\hline Male & $16.3 \pm 2.5$ & $16.2 \pm 5.7$ & 0.926 & $15-20$ \\
\hline Female & $16.0 \pm 3.5$ & $15.2 \pm 2.8$ & 0.596 & $15-20$ \\
\hline \multicolumn{5}{|c|}{ Total fat intake (g) } \\
\hline Male & $91.4 \pm 121.7$ & $89.5 \pm 16.6$ & 0.959 & $62-75$ \\
\hline Female & $46.9 \pm 9.6$ & $79.4 \pm 18.5$ & $0.001^{*}$ & $51-61$ \\
\hline \multicolumn{5}{|c|}{ Fat intake (\%) } \\
\hline Male & $35.0 \pm 6.5$ & $37.3 \pm 6.1$ & 0.327 & $25-30$ \\
\hline Female & $34.4 \pm 4.7$ & $36.4 \pm 6.1$ & 0.418 & $25-30$ \\
\hline
\end{tabular}

*significantly different between pre- and post-test at $p<0.05 ; N=21$

1. Instead of separating all these topics into individual sessions per week across several weeks, the present study decided to cover all the topics in a one-day class with three separate lectures, separated by lunch or tea breaks in between. To date, no method of topic distribution (either in one day or one session per week for several weeks) has proven to be effective in changing an individual's habit. However, exposure to all these topics, regardless of the method, is the major concern. Hence, this study chose to conduct the class in one day due to time constraint. The participants were university students who were used to a full day class. Hence, having a one-day class on sports nutrition with substantial breaks in between lectures was deemed tolerable.
Overall, sports nutrition knowledge among the participants had improved after attending the sports nutrition class, with majority of the participants categorised under high level of knowledge at post-test (Table 2), whereby the increment from moderate score to high score was significant in both genders (Table 3). This indicates that education has a positive impact on increasing the athletes' knowledge level. The finding of this study is consistent with the result findings from previous studies that focused on the implementation of nutrition education as an intervention (Siti Soraya et al., 2018; Rossi etal., 2017). In a previous research (Siti Soraya et al., 2018), 105 male team sports athletes were divided into experimental and control groups, where the experimental 
group received seven weeks of education intervention programme, while the control group did not. As a result, mean score for knowledge increased in the intervention group $(6.21 \pm 2.95)$ and decreased in the control group $(-2.15 \pm 1.45)$, providing further evidence that education is an effective tool for increasing an individual's knowledge level. A similar study was also conducted among adolescent cricket players, where both female and male athletes had poor understanding of sports nutrition (Sobana, 2016). Moreover, this previous study also found that female athletes showed better mean score in knowledge than male athletes.

Several factors contributed to the increase in nutrition knowledge among the participants during intervention. These factors included the content of the education, duration of the intervention programme, and the teaching techniques (Bratianu, 2015). To ensure maximum commitment from the participants, the content of teaching should be relevant and focused on the target audience, while the learning duration should not be too long or too frequent. Besides, to capture the participants' attention, they should be actively engaged during the learning process, thus a variety of teaching techniques should be implemented. In the present study, the sports nutrition class was held for one day with several breaks in between, and the teaching techniques included lectures, group discussions, and some group activities. Education background could be a determinant of the level of knowledge of an individual. According to a previous study, a population with a low educational level showed less correct answers concerning knowledge about the subject matter. Consequently, this might lead to low scores in attitude and practice (Diaz-Quijano et al., 2018). Participants in this study were recruited among university students who had not received any prior formal sports nutrition education.

The participants' attitudes on sports nutrition were also measured at pre- and post-test. There was improvement in attitude scores among participants from pre- to post-test in both genders, but it was only significant in female participants (Table 3). None of the participants showed negative attitude since the beginning of the study. This attitude is a strong predictor (Backman et al., 2002) and a vital one for athletes to practise eating a healthy diet (Shifflett, Timm \& Kahanov, 2002). In several previous studies, attitude scores have been significantly improved in primary school children after attending a nutrition education programme (Zalilah et al., 2008; Ruzita, Wan Azdie \& Ismail, 2007). A positive relationship between knowledge and attitude was reported among softball players, and higher nutrition knowledge led to a better attitude towards nutrition (Hornstrom et al., 2011). This can be attributed to an increase in awareness among individuals after receiving proper education. In this study, no participants showed a negative attitude towards sports nutrition. This might be due to their education background that makes them aware about the importance of correct nutrition. Furthermore, environmental factors, such as friends, family, and culture, might also influence their attitudes towards nutrition intake.

The mean score for dietary practice was significantly improved from poor to fair in both genders after attending the sports nutrition class (Tables 2 and 3). This implies that the sports nutrition class conducted was successful in improving participants' eating practices. This finding is supported by previous studies (Siti Soraya et al., 2018; Zalilah et al., 2008), which also reported increased mean score for practice following an 
education intervention. There are several factors affecting dietary practices and food choices among athletes. Food availability in their surroundings, knowledge about food, and family beliefs are among the major factors (Othman et al., 2013). Food choices by athletes are also likely to be influenced by their coaches. Some athletes are concerned about their weight and body image, particularly for weight-category sports or aesthetic sports, which contribute added pressure for them in food choices and the need to practise a healthy diet. Furthermore, the impact of media and social influences are also significant in food choices and dietary practices among athletes, aside from the general population (Birkenhead \& Slater, 2015).

The priority for athletes with regards to nutrition is meeting their energy needs. Athletes must consume foods that provide enough energy to maintain body weight and body composition, especially during training. The present study found a significant increase in mean total energy intake at post-test in both male and female participants (Table 4). Similarly, it was previously reported that total calorie intake improved among team sports athletes after receiving education intervention (Siti Soraya et al., 2018). Another study also reported similar findings; improvement in the overall energy intake as a result of sports nutrition education (MolinaLopez et al., 2013). According to the Malaysian RNI, several factors should be considered while determining the energy expenditure for an individual. These include socio-demography, body composition and body size, presence of any medical condition, level of physical activity, as well as surrounding environments (NCCFN, 2017; WHO, 2010).

As suggested by the RNI, total energy intake for non-athlete adult men aged 19 to 30 years old is between 2520 to
2740 kcal per day, and for non-athlete adult women of similar age, the range is between 2080 to $2370 \mathrm{kcal}$ per day (NCCFN, 2017). However, the total energy intake needed for athlete population is slightly higher, depending on the types of sports and training load. Based on the result of this study, although mean total energy intake had increased, the amount for both male and female participants did not meet the recommended values as suggested by the RNI (Table 4). Similarly, previous studies also discovered that the energy intake of the participants was below the recommended value even after receiving sports nutrition education (Molina-Lopez et al., 2013; Cholewa et al., 2015). Many factors could have contributed to this finding concern about body weight, inaccurate reporting of food intake, or even underor overestimation of the participants' calories. Athletes that are involved in gymnastics, wrestling, bodybuilding, and long-distance running, which focus too much on having a lean body are at higher risk of poor nutrient intakes (Williams, 2017). In this study, majority of the participants were final year undergraduate students with a very tight schedule. At the same time, they were actively involved in training and sports. Hence, having a busy lifestyle might be one of the reasons they were taking slightly less calories than what their requirement. It is most unlikely for them to under-report their dietary intake since they have been taught properly about the right way to report dietary intakes and the importance of reporting it with honesty.

The mean total carbohydrate intake per day had significantly increased from pre- to post-test, where the value at posttest was within the range recommended by RNI (Table 4). However, the percentage of carbohydrate intake at post-test was still below the RNI recommendation for carbohydrate intake, which is between 
$55 \%$ and $70 \%$ of total energy intake. This is due to the significant increase in protein and fat intakes at post-test by the participants. Total protein intake per day significantly increased beyond the recommended value by RNI, whereas for fat, its total intake was already high at pre-test and continued to be high even four weeks after attending the sports nutrition class.

These findings on dietary intake contradicted the KAP mean scores of the participants. Although the mean scores for knowledge, attitude, and practice among participants had increased, their actual dietary intake had not improved. Protein is responsible for rebuilding muscle tissues after exercise, and fat is a source of energy. Yet, diets high in protein and fat have not been shown to be beneficial for athletic performance, especially in the presence of inadequate carbohydrate ingestion (Loucks, 2004). Thus, meeting the recommended guidelines is very crucial, especially for the young athlete population.

\section{CONCLUSION}

This study revealed that a one-day sports nutrition class significantly increased the participants' knowledge, attitude, and practice scores in sports nutrition. However, the participants' dietary intake did not improve. The total intake per day of protein and fat were higher than the RNI even after attending the sports nutrition class. Future studies should give extra attention on protein and fat intakes as well as address all the limitations highlighted in this study.

\section{Acknowledgement}

The authors wish to thank all the participants and the Exercise and Sports Science Laboratory staffs of Health Campus, Universiti Sains Malaysia, for their commitment and cooperation in this study.

\section{Authors' contributions}

NNZKZ, principal investigator, conceptualised and designed the study, prepared the draft of the manuscript and reviewed the manuscript; ASM, advised on data analysis and interpretation, and reviewed the manuscript; MRCJ, advised on data analysis and interpretation, and reviewed the manuscript.

\section{Conflict of interest}

The authors declare no conflict of interests.

\section{References}

Arieli R \& Constantini N (2012). Energy balance among female athletes. Med Sci Sports Exerc $151(2): 82-85$.

Backman DR, Haddad EH, Lee JW, Johnston PK \& Hodgkin GE (2002). Psychosocial predictors of healthful dietary behavior in adolescents. $J$ Nutr Educ Behav 34(4):184-193.

Birkenhead KL \& Slater G (2015). A Review of Factors Influencing Athletes' Food Choices. Sp Med 45(11):1511-1522.

Bratianu C (2015). Organizational knowledge dynamics: Managing knowledge creation, acquisition, sharing, and transformation: Managing knowledge creation, acquisition, sharing, and transformation ( $2^{\text {nd }}$ Ed). IGI Global, Pennsylvania.

Cholewa JM, Landreth A, Beam S, Jones T \& MacDonald CJ (2015). The effects of a sports nutrition education intervention on nutritional status, sport nutrition knowledge, body composition, and performance in NCAA Division I baseball players. J Int Soc Sports Nutr 12(1):44

Deutz RC, Benardot D, Martin DE \& Cody MM (2000). Relationship between energy deficits and body composition in elite female gymnasts and runners. Med Sci Sports Exerc 32(3):659668.

Diaz-Quijano FA, Martínez-Vega RA, RodriguezMorales AJ, Rojas-Calero RA, Luna-González ML \& Diaz-Quijano RG (2018). Association between the level of education and knowledge, attitudes and practices regarding dengue in the Caribbean region of Colombia. BMC Public Health. 18(1): 143 .

Dunn D, Turner LW \& Denny G (2007). Nutrition knowledge and attitudes of college athletes. Sports J 10(4):45-52. 
Fink HH \& Mikesky AE (2018). Practical applications in sports nutrition ( $2^{\text {nd }} \mathrm{Ed}$ ). Jones \& Bartlett Learning, Burlington, Massachusetts.

Hornstrom GR, Friesen CA, Ellery JE \& Pike K (2011). Nutrition knowledge, practices, attitudes, and information sources of midAmerican conference college softball players. Food Nutri Sci 2(2):109-117.

Jacobson BH, Sobonya C \& Ransone J (2001). Nutrition practices and knowledge of varsity athletes: A follow-up. $J$ Strength Cond Res 15(1):63-68.

Kiens B, Ivy JL \& Burke LM (2004). Carbohydrates and fat for training and recovery. $J$ Sports Sci22(1):15-20.

Loucks A (2004). Energy balance and body composition in sports and exercise. $J$ Sports Sci22:1-14.

McArdle WD, Katch FI \& Katch VL (2013). Introduction in sports and exercise nutrition (4th Ed). Lippincott Williams \& Wilkins, Philadelphia.

Molina-Lopez J, Molina JM, Chirosa LJ, Florea D, Saez L, Jimenez J, Planells P, Perez de la Cruz A \& Planells E (2013). Implementation of a nutrition education program in a handball team, consequences on nutritional status. Nutrition Hospital 28(3):1065-1076.

NCCFN (2017). Recommended Nutrient Intakes for Malaysia. A Report of the Technical Working Group on Nutritional Guidelines. National Coordinating Committee on Food and Nutrition, Ministry of Health Malaysia, Putrajaya. From http://nutrition.moh.gov. my/wp-content/uploads/2017/05/FA-BukuRNI.pdf. [Retrieved January 11 2017].

Othman KI, Karim MS, Karim R, Adzhan NM \& Halim NA (2013). Consumption pattern on fruits and vegetables among adults: A Case of Malaysia. Acad J Interdiscip Stud 2(8):424-430.

Paugh SL (2005). Dietary habits and nutritional knowledge of college athletes. (Master of Science), California University of Pennsylvania, California, Pennsylvania. From http://libweb. calu.edu/thesis/umi-cup-1011.pdf. [Retrieved October 6 2005].

Rossi FE, Landreth A, Beam S, Jones T, Norton L \& Cholewa JM (2017). The effects of a sports nutrition education intervention on nutritional status, sport nutrition knowledge, body composition and performance during off season training in NCAA Division 1 baseball players. J Sci Med Sport 6:60-68.
Ruzita AT Jr, Wan Azdie MA \& Ismail MN (2007). The effectiveness of nutrition education programme for primary school children. Mal $\mathrm{J}$ Nutr 13(1):45-54.

Shifflett B, Timm C \& Kahanov L (2002). Understanding of athletes' nutritional needs among athletes, coaches, and athletic trainers. Res Q Exerc Sport 73(3):357-362.

Siti Soraya ME, Hazizi AS, Mohd Nasir MT \& Zubaidah J (2018). Effects of sports nutrition education intervention on sports nutrition knowledge, attitude and practice, and dietary intake of Malaysian team sports. Mal $\mathrm{J} \mathrm{Nutr}$ 24(1):103-116.

Sobana RM (2016). Sports nutritional knowledge, attitude and practice of adolescent cricket players. Int J Educ Res 12(2):129-131.

Trabucco G, Nikoic M \& Mirkovic BV (2013). Nutritional knowledge and behaviour among students practicing sports: comparison between two countries. Sci $J$ of the Faculty of Medicine in Nis 30(4):201-208.

WHO Expert Consultation (2004). Appropriate body-mass index for Asian populations and its implications for policy and intervention strategies. Lancet 363(9403):157-163.

WHO (2010). Nutrient profiling: report of a WHO/IASO technical meeting. World Health Organization. London, United Kingdom. From https://www.who.int/nutrition/publications / profiling/WHO_IASO_report2010.pdf. [Retrieved October 6 2010].

Williams MH (2007). Nutrition for health, fitness, and sport ( $\left.8^{\text {th }} E d\right)$. McGraw-Hill, New York.

Zalilah MS, Siti Sabariah B, Norlijah O, Normah H, Maznah I, Zubaidah J, Sham MK, Laily P, Bahaman AS \& Zabidi Azhar MH (2008). Nutrition education intervention improves nutrition knowledge, attitude and practices of primary school children: A pilot study. Int Electron J Health Educ 11:119-132. 